\title{
PELATIHAN DAN PENDAMPINGAN KADER POSYANDU LANSIA DI WILAYAH KERJA PUSKESMAS CIMUNING
}

\author{
Ihsana El Khuluqo ${ }^{*}$, Tati Nuryati ${ }^{1}$ \\ ${ }^{1}$ Sekolah Pascasarjana, Universitas Muhammadiyah Prof. DR. HAMKA, \\ Jalan Limau II, Kramat Pela, Kebayoran Baru, Jakarta Selatan 12130 \\ Email Penulis Korespondensi: ihsana_khuluqo@uhamka.ac.id
}

\begin{abstract}
Abstrak
Pengabdian masyarakat berjudul Pelatihan dan Pendampingan Kader Posyandu Lansia di Desa Cimuning Wilayah Kerja Puskesmas Cimuning bertujuan untuk membangun kesadaran masyarakat mengenai kesehatan pada usia lanjut. Metode pelaksanaan kegiatan pengabdian ini yaitu pendekatan persuasive dengan tahapan-tahapan pelaksanaan yaitu (1) melakukan pendekatan persuasive kepada masyarakat sebagai kader posyandu, (2) Penyuluhan kesehatan/ceranah interaktif, diskusi kelompok, tanya jawab, dan simulasi, (3) pemeriksaan fisik (4) serta pencatatan dan pelaporan hasil pemeriksaan isik kesehatan masyarakat lanjut usia. Di kelurahan Cimuning baru terbentuk 8 Posyandu Lansia dari $26 R W$ yang ada, sehingga perlu dibentuk lagi posyandu lansia pada $R W$ yang belum memiliki posyandu lansia. Dengan demikian Program Kerja Sama Mitra (PKM) dalam pengabdian masyarakat menawarkan solusi antara lain dengan pelatihan dan pendampingan kader posyandu lansia. Kegiatannya antara lain: Sosialisasi pentingnya posyandu lansia melalui Forum Kelurahan/RW, rekrutmen dan pelatihan kader posyandu lansia, layanan posyandu lansia, penyuluhan kesehatan, $P M T$, penimbangan, vitamin dan permainan-permainan yg menyenagkan dan menyehatkan, peningkatan kesehatan, komunikasi interpersonal yang bekerjasama dengan masyarakat sekitar. Kesimpulan bahwa pelatihan dan pendampingan kader posyandu lansia kelurahan Cimuning sangat bermanfaat dalam meningkatkan status kesehatan dan kualitas hidup lansia pelayanan kesehatan lansia di posyandu.
\end{abstract}

\section{Kata kunci : Lansia, Pengabdian, Posyandu}

\begin{abstract}
Community service titled Training and Assistance for Elderly Posyandu Cadres in Cimuning Village Cimuning Health Center Work Area aims to build public awareness about health in old age. The method of implementing this community service activity is a persuasive approach with stages of implementation, namely (1) carrying out a persuasive approach to the community as a posyandu cadre, (2) health education / interactive stories, group discussions, questions and answers, and simulations, (3) physical examinations (4) as well as recording and reporting the results of health examinations for the elderly. The elderly posyandu services emphasize promotive and preventive services without ignoring curative and rehabilitative efforts. In Cimuning Village, only 8 Elderly Integrated Healthcare Center was formed from 26 existing RWs, so it is necessary to re-establish elderly Integrated Healthcare Center for RWs that do not yet have elderly Integrated Healthcare Center. Therefore the Partnership Cooperation Program in community service offers solutions including, among others, training and mentoring for elderly Integrated Healthcare Center cadres. The activities socialization of the importance of Integrated Healthcare Center for the elderly through the Village Office Forum, recruitment and training of elderly Integrated Healthcare Center cadres, elderly Integrated Healthcare Center services, health counseling, supplementary feeding, weighing, vitamins and games that are fun and healthy, improving health, interpersonal communication in collaboration with surrounding communities. The Conclusion that the training and assistance of elderly Integrated Healthcare Center cadres in Cimuning
\end{abstract}


Village are very useful in improving the health status and quality of life of elderly health services in the Integrated Healthcare Center.

\section{Keywords: Integrated Healthcare Center, Elderly, Devotion}

\section{PENDAhuluan}

Lansia merupakan proses yang terjadi secara alami pada setiap individu dimana dalam setiap proses ini terjadi perubahan fisik maupun mental yang akan berpengaruh pada berbagai fungsi dan kemampuan tubuh yang pernah dimilikinya. Menurut Undang-Undang Republik Indonesia Nomor 13 Tahun 1998 tentang kesejahteraan lanjut usia bab 1 pasal 1 ayat 2, lanjut usia adalah seseorang yang telah mencapai usia 60 tahun ke atas. Berdasarkan data proyeksi penduduk oleh Departemen Kesehatan (2006), diperkirakan tahun 2017 terdapat 23,66 juta jiwa penduduk lansia di Indonesia (9,03\%). Diprediksi jumlah penduduk lansia tahun 2020 (27,08 juta), tahun 2025 (33,69 juta), tahun 2030 (40,95 juta), dan tahun 2035 (48,19 juta). Badan Pusat Statistik (2017) dalam publikasinya juga menyebutkan dalam waktu hampir lima dekade, persentase lansia Indonesia meningkat sekitar dua kali lipat (1971-2017), yakni menjadi 8,97 persen $(23,4$ juta) di mana lansia perempuan sekitar satu persen lebih banyak dibandingkan lansia lakilaki (9,47 persen banding 8,48 persen). Selain itu, lansia Indonesia didominasi oleh kelompok umur 60-69 tahun (lansia muda) yang persentasenya mencapai 5,65 persen dari penduduk Indonesia, sisanya diisi oleh kelompok umur 70-79 tahun (lansia madya) dan 80+ (lansia tua).

Menurut WHO dan Undang-Undang No. 13 Tahun 1998 (kompasiana.com, 2019) tentang kesejahteraan lanjut usia pada pasal 1 ayat 2 menyebutkan bahwa umur 60 tahun adalah usia permulaan tua. Menua bukanlah suatu penyakit, akan tetapi merupakan proses yang berangsurangsur mengakibatkan perubahan yang kumulatif, merupakan proses menurunnya daya tahan tubuh dalam menghadapi rangsangan dari dalam dan luar tubuh yang berakhir dengan kematian. Pada dasarnya proses menua ditandai dengan berbagai perubahan-perubahan sebagai berikut:

a. Perubahan perilaku dan masalah psikologis karena kehilangan pasangan hidup, ditinggal anak yang telah menikah, penurunan fungsi penglihatan dan pendengaran, adanya penyakit kronis atau degeneratif, mobilitas terbatas, kesepian dan penghasilan berkurang.

b. Perubahan pada organ tubuh, dimana pada sistem organ pada lansia rawan terkena penyakit diantaranya diabetes mellitus, stroke, gagal ginjal, kanker, hipertensi, dan jantung.

Masalah kesehatan pada lansia tentu saja berbeda dengan jenjang umur yang lain karena penyakit pada lansia merupakan gabungan dari kelainan-kelainan yang timbul akibat penyakit dan proses menua yaitu proses menghilangnya secara perlahan-lahan kemampuan jaringan untuk memperbaiki diri atau mengganti sel serta mempertahankan struktur dan fungsi normalnya, sehingga tidak dapat bertahan terhadap infeksi dan memperbaiki kerusakan yang diderita. Masalah yang terjadi pada lansia diantara lain sakit gigi $2,48 \%$, diare $3,05 \%$, asma $11,09 \%$, panas $17,83 \%$, sakit kepala $19,52 \%$, pilek $21,52 \%$, batuk $33,89 \%$ dan lainnya 63,68\% (Infodatin, 2014). Sedangkan menurut Kemenkes, pada tahun 2013 keluhan kesehatan lansia yang paling tinggi adalah keluhan yang merupakan efek dari penyakit kronis seperti asam urat, darah tinggi, rematik, darah rendah dan diabetes (Infodatin, 2014).

Data penyakit lansia di Indonesia (umumnya pada lansia berusia lebih dari 55 tahun) adalah sebagai berikut (a) Penyakit Cardiovascular, (b) Penyakit otot dan persendian, (c) Bronchitis, asma dan penyakit respirasi lainnya (d) Penyakit pada mulut, gigi dan saluran cerna, (e) Penyakit syaraf, (f) Infeksi kulit, (g) Malaria, (h) Lainlain.

Melihat berbagai permasalahan baik fisik maupun psikologis yang sering dialami pada lansia maka dirasa perlu untuk mengadakan pelatihan serta pendampingan dalam rangka mewujudkan masa tua yang berguna dan bahagia lansia melalui program posyandu lansia. Dalam program ini, perencanaan yang dilakukan ialah dengan melakukan sosialisasi mengenai pentingnya posyandu lansia melalui forum masyarakat tingkat RW/Kelurahan Cimuning. Kemudian rekrutmen kader posyandu lansia melalui musyawarah tingkat RW kelurahan 
Cimuning. Pelatihan kader Posyandu lansia tentang pelaksanaan posyandu lansia (pelayanan 5 meja, cara mengisi dan membaca KMS lansia, mengukur tekanan darah dan nadi serta rencana tindak lanjut.

\section{Identifikasi Masalah}

Berdasarkan keterangan dari Kelurahan Cimuning jumlah penduduk pra lansia (45-59 tahun) di Kelurahan Cimuning sebanyak 1.759 orang terdiri dari 851 orang laki-laki dan 908 orang perempuan. Jumlah penduduk lansia (6069 tahun) sebanyak 488 orang terdiri dari 259 orang laki-laki dan 229 orang perempuan, Sedangkan jumlah lansia berisiko tinggi (70 tahun ke atas) sebanyak 139 orang terdiri dari 66 orang laki-laki dan 73 perempuan. Total keseluruhan penduduk pra lansia sampai dengan lansia berisiko sebanyak 2.386 orang tersebar di 26 RW di kelurahan Cimuning Wilayah Kerja Puskesmas Cimuning, Mustikajaya, Kota Bekasi.

Penyakit yang sering dialami oleh kelompok usia lanjut diantaranya adalah Diabetes Melitus, hypertensi, osteoporosis, osteoarteristis, jantung koroner, dan lain sebagainya. Berdasarkan laporan bulanan Puskesmas Cimuning diperoleh data penyakit tidak menular (PTM) dari bulan Januari- Agustus tahun 2018 yang terbanyak adalah penyakit hypertenis sebanyak 459 kasus terdiri dari perempuan 362 kasus dan laki-laki 97 kasus. Disusul kemudian penyakit Disbetes
Melitus (kencing manis) sebanyak 107 kasus terdiri dari perempuan 106 kasus dan laki-laki 65 kasus.

Salah satu upaya mengatasi masalah kesehatan lansia adalah dibentuknya posyandu lansia di setiap RW, dimana Posyandu lansia merupakan fasilitas pelayanan kesehatan lansia berbasis masyarakat bertujuan untuk mewujudkan masa tua yg bahagia dan berdayaguna. Dari $26 \mathrm{RW}$ yang ada di Kelurahan Cimuning baru terdapat $8 \mathrm{RW}$ yang memiliki Posyandu lansia, sisanya sebanyak 18 RW belum memiliki Posyandu lansia.

Mengingat banyaknya lansia berisiko tinggi di Kelurahan Cimuning dan masih minimnya jumlah Posyandu lansia, maka perlu diadakan pelatihan dan pendampingan Posyandu lansia kerjasama Puskesmas Cimuning dan LPPM Sekolah Pascasarjana UHAMKA pada tahun 2019.

\section{METODE PELAKSANAAN}

Metode pelaksanaan meliputi (1) Pendekatan persuasif, (2) Penyuluhan kesehatan/ceranah interaktif, diskusi kelompok, Tanya jawab, simulasi, (3) Pemeriksaan fisik (4) Pencatatan dan pelaporan.

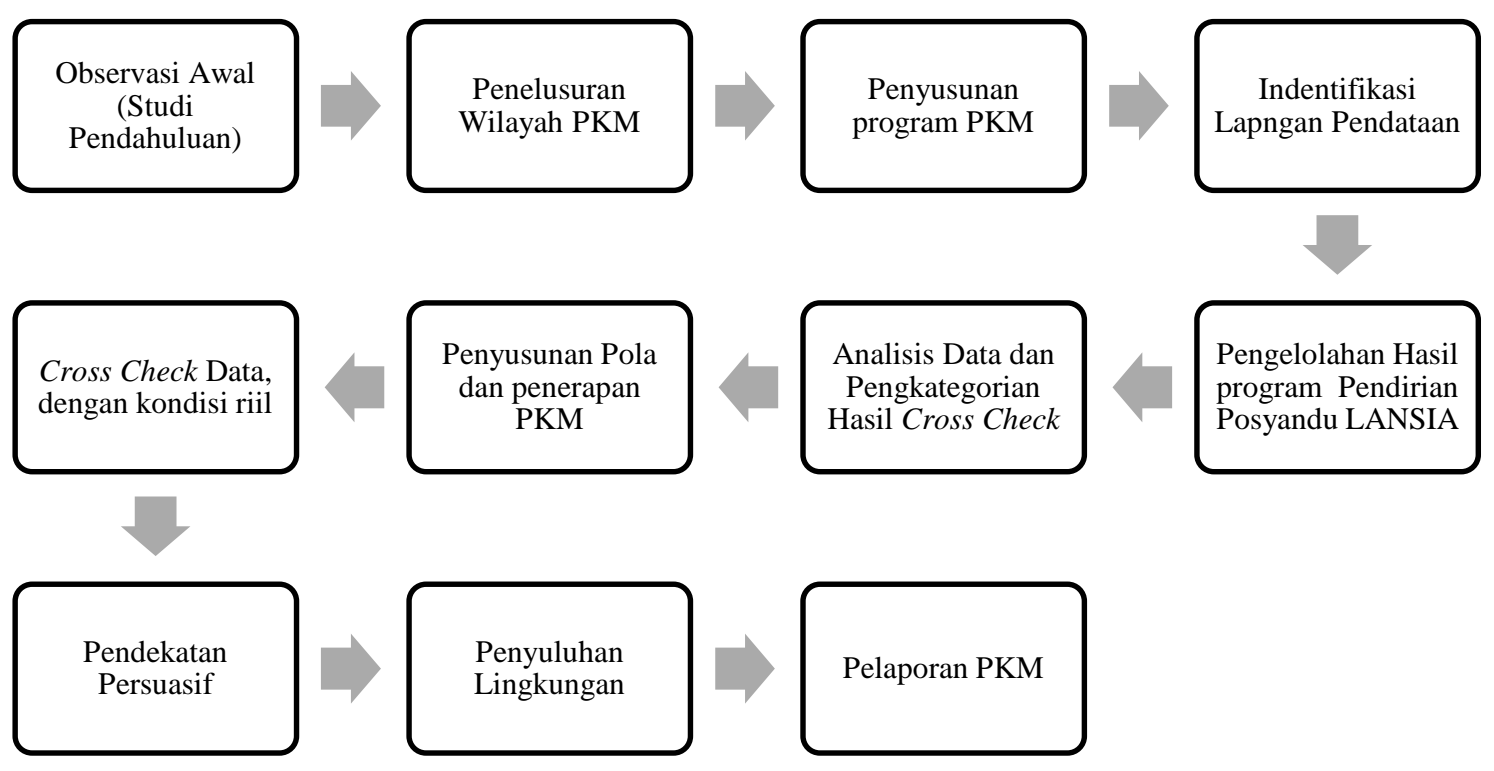

Gambar 1. Diagram alir metode pelaksanaan kegiatan pengabdian masyarakat 


\section{HASIL DAN PEMBAHASAN}

Dengan terselenggaranya program pembentukan dan pelatihan kader posyandu lansia di desa Cimuning Wilayah Kerja Puskesmas Cimuning Kecamatan Mustikajaya Kota Bekasi didapat hasil bahwa sarana dan prasarana kesehatan untuk lansia di Posyandu ini masih kurang memadai ditambah dengan sarana dan prasarana yang tidak tersedia sesuai dengan kebutuhan. Seperti misalnya tidak tersedia thermometer dewasa, pengukur tinggi badan, kursi roda, antiseptik, dan baskom cuci tangan serta berbagai peralatan standar kesehatan lansia lainnya. Masalah yang terjadi pada lansia diantara lain sakit gigi $2,48 \%$, diare $3,05 \%$, asma $11,09 \%$, panas $17,83 \%$, sakit kepala $19,52 \%$, pilek $21,52 \%$, batuk 33,89\% dan lainnya 63,68\% (Infodatin, 2013). Sedangkan menurut Kemenkes, 2013 keluhan kesehatan lansia yang paling tinggi adalah keluhan yang merupakan efek dari penyakit kronis seperti asam urat, darah tinggi, rematik, darah rendah dan diabetes. Dari Pengabdian Masyarakat ini, akan memberikan solusi dengan mendirikan Posyandu Lansia guna memberikan edukasi tentang preventif dalam kemungkinan terserangnya penyakit, antara lain : (1) Penyakit Cardiovascular, (2) Penyakit otot dan persendian, (3) Bronchitis, asma dan penyakit respirasi lainnya seperti influenza, faringitis, laryngitis, emfisena, pneumonia, dan kanker paru-paru (4) Penyakit pada mulut, gigi dan saluran cerna, (5) Penyakit syaraf, (6) Infeksi kulit, (7) Malaria. Selain memberikan cara bagaimana mengetahui standarisasi makanan sehat, penimbangan, serta menjaga kebersihan lingkungan. Program pembentukan dan pelatihan kader posyandu lansia di desa Cimuning Wilayah Kerja Puskesmas Cimuning ini berhasil berjalan dengan indikator-indikator yang menunjukan keberhasilan yaitu Posyandu lansia terbentuk dan berjalan, (2) terdapat kegiatan rutin setiap minggu,

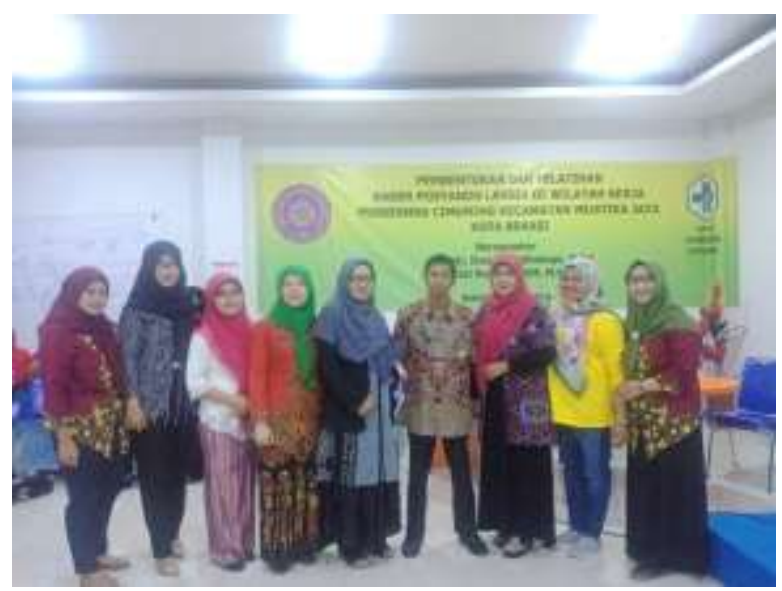

Gambar 2. Pembentukan dan Pelatihan Kader Posyandu Lansia

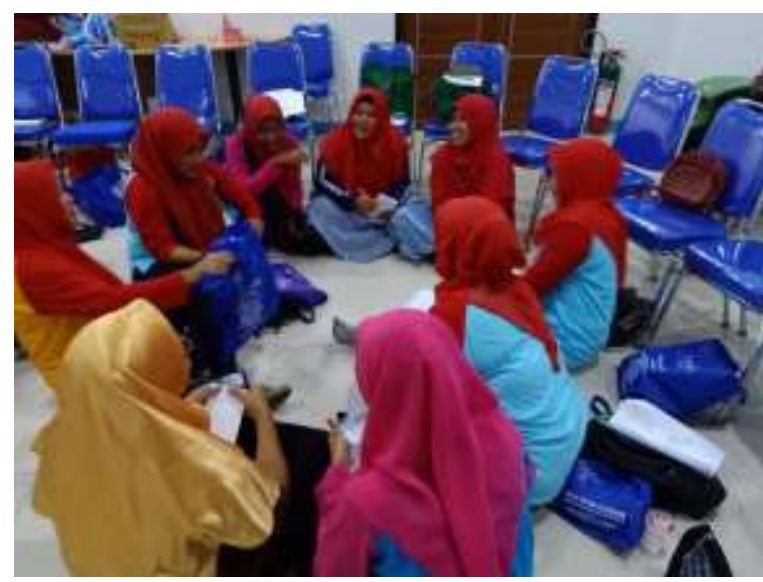

Gambar 3. Pembentukan Kader Posyandu Lansia

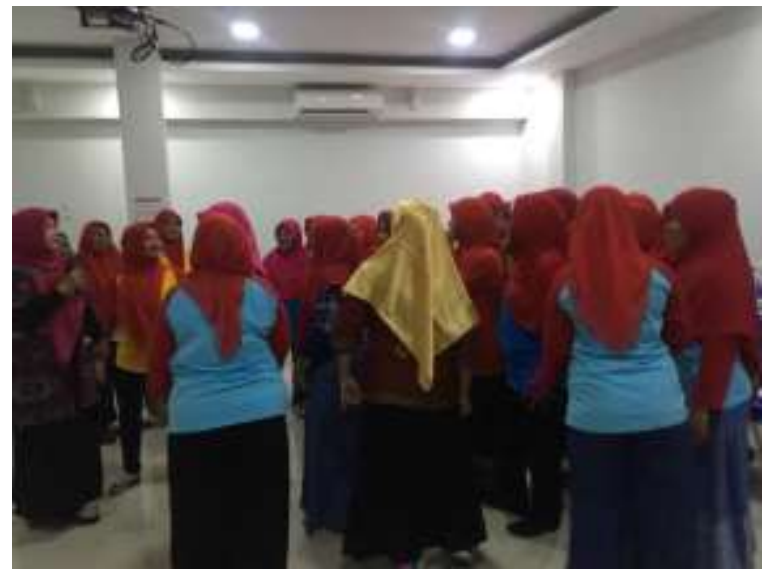

Gambar 4. Membangun Persepsi 


\section{SIMPULAN DAN SARAN}

Peningkatan kapasitas kader posyandu Cimuning dalam kegiatan pelatihan sangat bermanfaat demi kemajuan dan peningkatan kinerja Posyandu Cimuning. Dilihat dari berbagai permasalahan yang sering terjadi pada lansia seperti masalah fisiologis (fungsi tubuh menurun) dan masalah psikologis (kesepian) serta berbagai penyakit yang sering diderita lansia seperti pnemonia, penyakit paru, gagal jantung, nyeri sendi, dan infeksi saluran kemih. Maka Kelurahan cimuning dianjurkan untuk mencanangkan posyandu lansia menuju masyarakat cimuning sehat mandiri. Salah satu cara yang dapat dilakukan untuk meningkatkan kesejahteraan lansia baik fisik maupun psikologis melalui kegiatan posyandu lansia yang mandiri dalam masyarakat. Manfaat posyandu lansia adalah agar lansia mampu mempertahankan kesehatan fisik agar selalu bugar dan mempertahankan kesehatan psikologis lansia. Standar pelayanan dalam rangka meningkatkan pelayanan bagi para lansia ialah dengan menerapkan standar pelayanan minimal 5 meja.

\section{DAFTAR PUSTAKA}

Badan Pusat Statistik. (2017). Statistik Penduduk Usia Lanjut. http://www.bps.go.id/ diakses pada 24 Juli 2019.

Departemen Kesehatan RI. (2006). Pedoman Umum Pengolalaan Posyandu. http://promkes.kemkes.go.id/pedomanumum-pengelolaan-posyandu.

Kementrian Kesehatan RI. (2014). Situasi dan Analisis Lanjut Usia. Jakarta: Pusat data dan Informasi Kementrian Kesehatan RI.

Kompasiana.com. Lansia yang Tangguh dan Sehat. dapat diakses di https://www.kompasiana.com/penaulum/5d 5139a90d82300cc250eca2/lansia-yangtangguh-dan-sehat

Undang - Undang No. 13 Tahun 1998 tentang Kesejahteraan Lanjut Usia 